\title{
Using a nomogram based on preoperative serum fibrinogen levels to predict recurrence of papillary thyroid carcinoma
}

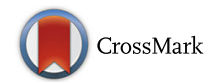

\author{
Lei Jianyong, Li Zhihui, Gong Rixiang and Zhu Jingqiang*
}

\begin{abstract}
Background: Hyperfibrinogenemia is increasingly being recognized as an important risk factor related to cancer stage, development and outcomes. We evaluated whether preoperative serum fibrinogen levels predict recurrence of papillary thyroid carcinoma (PTC).

Methods: We retrospectively collected data for 1023 PTC patients who underwent surgery at our institution from Aug 2014 to Aug 2016. In total, 414 patients (from Aug 2014 to Dec 2015) were used as the training set to build the model, and 609 patients (from Jan 2016 to Aug 2016) were used as the testing set to validate the model.

Results: In the training set, PTC cases with high serum fibrinogen levels were more likely to have multiple PTCs ( $P=0$. 001 ) and to exhibit surrounding tissue or organ invasion (both $P<0.01$ ). Moreover, PTC patients with higher serum fibrinogen levels were also more likely to have an advanced tumor stage $(T, P=0.001)$ and distance metastasis $(P<0$. 001), and these patients had a significantly higher rate of postoperative PTC recurrence $(P=0.002)$. All of these findings were validated in the testing set. The results of univariate and multivariate analyses indicated that hyperfibrinogenemia was a risk factor for PTC recurrence. The identified risk factors were incorporated into a nomogram and validated using the testing set (C-index $=0.811,95 \% \mathrm{Cl}: 0.762-0.871)$.

Conclusion: PTC cases with hyperfibrinogenemia are more likely to have an advanced TNM stage and have a higher rate of PTC recurrence. Our nomogram could be used to objectively and accurately predict PTC recurrence in a clinical setting.
\end{abstract}

Keywords: Papillary thyroid carcinoma, Fibrinogen, Lymph node metastasis, Recurrence

\section{Background}

Papillary thyroid carcinoma (PTC) has rapidly increased in recent years [1,2], mainly because of the use of ultrasonography (US) and US-guided fine-needle aspiration cytology (FNAC) during preoperative diagnosis [3]. PTC is usually indolent and curable via surgical thyroidectomy followed by TSH suppression or radioiodine treatment. However, lymph node metastases (LNM) develop in approximately $30-80 \%$ of PTC patients [4]. LNM increases the risk of locoregional recurrence and may influence cancer-specific survival in some patients with PTC [5]. Because $60-75 \%$ of disease recurrences in the neck occur in the lymph nodes, detecting LNM during

\footnotetext{
* Correspondence: zjqdoctor@163.com

Thyroid and Parathyroid Surgery Group of West China Hospital of Sichuan University, Chengdu, China
}

the initial operation is very important to reduce the reoperation rate and decrease associated risks and complications [6]. However, the sensitivity of preoperative US for diagnosing central compartment lymph node metastasis is low, ranging from $27.3 \%$ to $55 \%$ [7], mainly because of air in the trachea. Moreover, fine-needle aspiration (FNA) may also be limited to patients diagnosed with central compartment lymph node metastasis because of the risk of recurrent laryngeal nerve injury.

Fibrinogen is a 350-Kda glycoprotein that is synthesized mainly by the liver epithelium [8] and is recognized as one of several acute phase reactant proteins that is produced during systemic inflammation or tissue injury. Fibrinogen that has been converted to insoluble fibrin by activated thrombin can significantly affect blood clotting, the inflammatory response, fibrinolysis, 
wound healing and neoplasia [9]. Moreover, previous studies have reported that increased fibrinogen activity significantly influences cancer cell growth, progression and metastasis in lung [10], colorectal [11], cervical [12], ovarian [13], esophageal [14], and pancreatic [15] cancer. Furthermore, plasma fibrinogen levels have been associated with tumor size, tumor invasion and lymph node metastasis in a variety of cancers and is recommended as a useful predictor of lymphatic metastasis in gastric cancer [16], non-small cell lung cancer [10], and colorectal cancer [17]. Potential mechanisms of fibrinogen in cancer include angiogenesis stimulation [18], tumor cell proliferation enhancement [19] and immune cell restriction [20]. However, whether serum fibrinogen concentrations represent a significant predictor of tumor stage or recurrence in PTC patients remains unclear and unexplored. Therefore, in the present study, we analyzed the correlations between preoperative serum fibrinogen levels and tumor characteristics and tested the value of using preoperative serum fibrinogen levels as a biomarker for predicting PTC recurrence.

\section{Methods}

\section{Study design}

In the present study, we enrolled 1023 PTC patients, who were divided into the following two independent groups: a training set that comprised 414 consecutive patients and a testing set that comprise 609 consecutive patients with thyroidectomy who were admitted to West China Hospital of Sichuan University (Chengdu, China) between Aug 2014 and Dec 2015 and between Jan 2016 and Aug 2016, respectively. Clinical baseline data were retrospectively collected for each patient from the HIS medical system of our hospital, informed consent was preoperatively obtained from all patients, and this clinical study was approved by the Ethics Committee of West China Hospital. The study was conducted in accordance with the ethical standards of the World Medical Association Declaration of Helsinki. PTC diagnoses, surgical procedures and postoperative follow-up protocols were performed as described in our previous studies [21, 22]: all patients accepted the initial followup at 1 month after surgery. The main items investigated were TSH, FT3 and FT4 levels in all cases, and Tg and $\mathrm{TgAb}$ in total thyroidectomy cases, which were assessed at the 1-month follow-up, and then every 3 months during the first year followed by every 6 months thereafter. Neck ultrasonography was performed and evaluated in the third month after surgery and then every 6-12 months. A $30 \mathrm{mCi}$ 131I scan was used to detect distant metastasis. We defined PTC recurrence as a structurally incomplete response during the short-term follow-up, as described in the ATA guidelines [2] and other reports [23, 24].

\section{Inclusion and exclusion criteria}

PTC patients who underwent thyroidectomy in our hospital were included in the present study. Patients in this initial group were excluded based on the following criteria: a history of thyroid surgery; other thyroid cancer, such as medullary or follicular thyroid cancer; no data for preoperative plasma fibrinogen level; a concomitant disease suspected of influencing serum fibrinogen concentrations, such as liver fibrosis or other liver disease; acute or chronic renal failure; severe hypertension; coagulation disorder; and anticoagulation therapy within 3 months prior to baseline testing to determine serum fibrinogen levels.

\section{Serum fibrinogen measurement}

A test to determine a patient's preoperative serum fibrinogen level is a routine and essential test that is performed in all PTC patients who undergo surgery. In this test, $2-3 \mathrm{ml}$ of whole blood is obtained via a peripheral venous puncture 1-3 days before surgery at 07:00 am and evaluated using classical methods (Sysmex XN$\left.9100^{\mathrm{mm}}\right)$. As one of seven coagulation functions, serum fibrinogen concentrations were analyzed as a continuous variable according to the reference value in our hospital, and the normal reference range for plasma fibrinogen concentrations was defined as between 2 and $4 \mathrm{~g} / \mathrm{L}$. Hence, hyperfibrinogenemia was defined as a plasma fibrinogen concentration $>4 \mathrm{~g} / \mathrm{L}$.

\section{Univariate and multivariate analysis of PTC recurrence}

All factors that were potential risk factors for PTC recurrence were included in the univariate analysis. Preoperative factors, including patient age $(\leq 45$ and $>45$ or $\leq 55$ and $>55$ ); gender (female or male); race (Han, $\mathrm{Ti}$ betan or other); smoking (yes/no); alcohol use (yes/no); intraoperative factors, including total thyroidectomy (yes/no) and central compartment lymph node dissection (yes/no); and histological factors, including $\mathrm{T}$ stage (T1-T2/T3-T4), N (N1/N0), M (M1/M0), PTC number (single/multiple), bilateral lobe PTC (yes/no), AJCC stage (I-II/III-IV) and postoperative RAI (yes/no). A univariate analysis was used to compare cases with present and absent PTC recurrence. Results with a $P$ value equal to or lower than 0.05 were analyzed in a multivariate analysis using Cox's proportional hazards regression model with a forward stepwise procedure.

\section{Statistical analysis}

All data were entered into an Excel file and then into SPSS. The statistical analysis was performed using SPSS 22.0 for Windows (IBM Corporation, Armonk, USA). Continuous variables are expressed as the mean \pm standard deviation, and categorical variables are expressed as percentages (\%). A chi-square test and Mann-Whitney 
U-test were performed to analyze the relationships between preoperative serum fibrinogen levels and PTC recurrence or other clinicopathological variables. Based on the identified risk factors, a nomogram of risk factors associated with PTC recurrence was established in R software studio. The predictive performance of this model was evaluated in the test group using the concordance index (C-index). A $P$ value lower than 0.05 in a two-tailed test was considered to indicate a significant difference.

\section{Results}

\section{Patient characteristics and PTC features}

The characteristics of the patients and their tumor features are summarized in Table 1 . Alcohol use $(p=0.027)$ , BRAF mutation $(p=0.030)$ and T classification $(p=0$. $016)$ were significantly different between the training set and the testing set, possibly due to the selection process. These differences may also indicate that our predictive model can be universally applied across heterogeneous populations of PTC patients.

\section{Associations between serum fibrinogen levels and clinicopathological features}

The serum fibrinogen levels were $2.71 \pm 0.57 \mathrm{~g} / \mathrm{L}$ in the training set and $2.96 \pm 0.65 \mathrm{~g} / \mathrm{L}$ in the testing set. The associations between serum fibrinogen levels and clinicopathological features in PTCs are shown in Table 2. Serum fibrinogen levels were positively correlated with PTC nodule number $(P=0.001$ in the training set and $P<0.001$ in the testing set), invasion (including the strap muscles, RLN, esophagus, and trachea; all $P$ values were less than 0.01 in both the training and testing group). Moreover, in PTC patients, higher serum fibrinogen levels were associated with advanced tumor stage ( $T$, $P=0.001$ in both sets $)$ and distant metastasis $(P<0.001$ in both sets) but not local lymph node metastasis $(P=0$. 186 and $P=0.604)$. Moreover, high preoperative serum fibrinogen levels were significantly associated with a higher incidence of postoperative PTC recurrence $(P=0$. 002 in both sets).

\section{The correlation between serum fibrinogen levels and prognosis in PTC patients}

As shown in Table 2, PTC patients with high serum fibrinogen levels had a higher rate of postoperative recurrence. To further investigate the prognostic value of serum fibrinogen in clinical outcomes, we conducted a Kaplan-Meier analysis according to serum fibrinogen levels. A log-rank test was used to compare PTC patients with high and low serum fibrinogen levels in the training, testing and combined sets. Tumor-free survival was significantly lower in patients with high serum fibrinogen levels in the training (as shown in Fig. 1a, $P=$
Table 1 Demographic and Clinicopathological Characteristics of Patients With PTC

\begin{tabular}{|c|c|c|c|c|}
\hline \multirow[b]{3}{*}{ Factor } & \multicolumn{2}{|c|}{ Training set } & \multicolumn{2}{|c|}{ Testing set } \\
\hline & \multicolumn{2}{|c|}{ Patients } & \multicolumn{2}{|c|}{ Patients } \\
\hline & No. & $\%$ & No. & $\%$ \\
\hline All patients & 414 & 100 & 609 & 10 \\
\hline \multicolumn{5}{|l|}{ Age (years) } \\
\hline$\leq 45$ & 242 & 58.5 & 347 & 57 \\
\hline$>45$ & 172 & 41.5 & 262 & 43 \\
\hline
\end{tabular}

Age (years)

$\begin{array}{lllll}\leq 55 & 357 & 86.2 & 500 & 84.0\end{array}$

$\begin{array}{lllll}>55 & 57 & 13.8 & 109 & 16.0\end{array}$

Gender

$\begin{array}{lllll}\text { Female } & 305 & 73.7 & 426 & 82.1\end{array}$

Male

Postoperative RAI

$\begin{array}{lllll}\text { Yes } & 228 & 55.1 & 344 & 56.5 \\ \text { No } & 186 & 44.9 & 265 & 43.5\end{array}$

Race

Han

Tibetan

Other†

Smoking

Never

Quit

Ongoing

Alcohol use

Never

Quit

Ongoing

BRAF mutation

Positive

Negative

Unknown

T classification

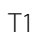

T2

T3

T4

$\mathrm{N}$ classification

NO

N1a

N1b

Distant metastasis

$\begin{array}{llll}109 & 26.3 & 183 & 17.9\end{array}$

\subsection{9}

0.079

0.196

0.655

0.971

$\begin{array}{llll}403 & 97.3 & 593 & 97.4\end{array}$

$\begin{array}{llll}3 & 0.7 & 6 & 1.0\end{array}$

$\begin{array}{llll}8 & 1.9 & 10 & 1.6\end{array}$

0.603

$\begin{array}{llll}352 & 84.5 & 508 & 83.4\end{array}$

$\begin{array}{llll}17 & 4.1 & 23 & 3.8\end{array}$

$\begin{array}{llll}45 & 10.9 & 78 & 12.8\end{array}$

0.027

$\begin{array}{llll}358 & 86.0 & 490 & 80.5\end{array}$

$\begin{array}{llll}3 & 0.7 & 14 & 2.3\end{array}$

$\begin{array}{llll}53 & 12.8 & 105 & 17.2\end{array}$

0.030

$\begin{array}{llll}51 & 12.3 & 128 & 21.0\end{array}$

$\begin{array}{llll}77 & 18.6 & 88 & 14.4\end{array}$

$\begin{array}{llll}286 & 68.6 & 393 & 64.5\end{array}$

0.016

$\begin{array}{llll}160 & 38.6 & 197 & 32.3\end{array}$

$\begin{array}{llll}11 & 2.7 & 13 & 2.1\end{array}$

$\begin{array}{llll}188 & 45.4 & 294 & 48.3\end{array}$

$\begin{array}{llll}55 & 13.3 & 105 & 17.2\end{array}$

0.605

48.1

32.3

19.5

No

Yes

No

410

4
99.0

1.0 
Table 1 Demographic and Clinicopathological Characteristics of Patients With PTC (Continued)

\begin{tabular}{|c|c|c|c|c|c|}
\hline \multirow[b]{3}{*}{ Factor } & \multirow{2}{*}{\multicolumn{2}{|c|}{$\begin{array}{l}\text { Training set } \\
\text { Patients }\end{array}$}} & \multirow{2}{*}{\multicolumn{2}{|c|}{$\begin{array}{l}\text { Testing set } \\
\text { Patients }\end{array}$}} & \multirow[t]{3}{*}{$P$ Value } \\
\hline & & & & & \\
\hline & No. & $\%$ & No. & $\%$ & \\
\hline PTC number & & & & & 0.135 \\
\hline Single & 355 & 85.7 & 536 & 88.0 & \\
\hline Multiple & 59 & 14.3 & 73 & 12.0 & \\
\hline Bilateral lobe PTC & & & & & 0.010 \\
\hline Yes & 47 & 11.4 & 41 & 6.7 & \\
\hline No & 367 & 88.6 & 568 & 93.3 & \\
\hline
\end{tabular}

0.001), testing (Fig. 1b, $P<0.001$ ) and combined (Fig. 1c, $P<0.001)$ sets.

\section{Univariate and multivariate analyses of PTC recurrence}

As shown in Table 3, univariate Cox regression analysis revealed that the following clinical factors are significantly associated with PTC recurrence: $\mathrm{T}$ classification (T1-2 vs T3-4, $P=0.021$ ), $\mathrm{N}$ classification (N0 vs N1, $P$ $=0.048), \mathrm{M}$ classification (M0 vs M1, $P<0.001$ ) and serum fibrinogen level (high vs low, $P=0.012$ ) in the training set; and $\mathrm{T}$ classification $(\mathrm{T} 1-2$ vs $\mathrm{T} 3-4, P=0$. 008), N classification (No vs N1, $P=0.041$ ), M classification (M0 vs M1, $P<0.001$ ) and serum fibrinogen level (high vs low, $P=0.007$ ) in the testing set. As shown in Table 4, multivariate analysis showed that T/N/M classification and high serum fibrinogen levels were independent prognostic factors of PTC recurrence in the training and testing sets.

\section{Nomogram for PTC recurrence}

The risk factors that were found to predict PTC recurrence in the training set were incorporated into the PTC recurrence nomogram. Although AJCC stage is a major risk factor for PTC recurrence, in the nomogram, it was not considered a direct factor. Therefore, we used $\mathrm{T}$ classification, $\mathrm{N}$ classification and serum fibrinogen levels to build the nomogram, as shown in Fig. 2. Moreover, although metastasis was a risk factor, we did not use it in the nomogram because metastasis is associated with a $100 \%$ recurrence rate according to our definition of PTC recurrence. For an individual nodule, the value is loaded on each variable axis (the 2nd-4th lines) and a line is drawn upwards to determine the number of points received for each variable (the 1st line). The sum of these numbers is located on the total points axis (the 5th line), and a line is drawn downwards to the risk axis (the 6th line) to determine the likelihood of PTC recurrence. In the validation cohorts used with the testing set, the C-index in the PTC recurrence nomogram was 0 . 811 (95\% CI, 0.762-0.871). The nomogram further
Table 2 Relationship between serum fibrinogen levels and clinical characteristics in the training and testing sets of PTC patients

\begin{tabular}{|c|c|c|c|c|c|c|}
\hline \multirow[b]{3}{*}{ Factor } & \multicolumn{3}{|c|}{ Training set } & \multicolumn{3}{|c|}{ Testing set } \\
\hline & \multicolumn{3}{|c|}{ Serum fibrinogen level } & \multicolumn{3}{|c|}{ Serum fibrinogen level } \\
\hline & Low & High & $p$ & Low & High & $p$ \\
\hline All patients & 402 & 12 & & 575 & 34 & \\
\hline Age (years) & & & 0.017 & & & 0.693 \\
\hline$\leq 45$ & 239 & 3 & & 328 & 18 & \\
\hline$>45$ & 163 & 9 & & 247 & 16 & \\
\hline Age (years) & & & 0.046 & & & 0.378 \\
\hline$\leq 55$ & 349 & 8 & & 474 & 26 & \\
\hline$>55$ & 53 & 4 & & 101 & 8 & \\
\hline Gender & & & 0.441 & & & 0.394 \\
\hline Female & 295 & 10 & & 400 & 26 & \\
\hline Male & 107 & 2 & & 175 & 8 & \\
\hline Postoperative RAI & & & 0.683 & & & 0.884 \\
\hline Yes & 221 & 7 & & 324 & 20 & \\
\hline No & 181 & 5 & & 251 & 14 & \\
\hline Race & & & 0.215 & & & 0.906 \\
\hline Han & 392 & 11 & & 560 & 33 & \\
\hline Other & 10 & 1 & & 15 & 1 & \\
\hline
\end{tabular}

BRAF mutation

0.642

Positive

Negative

Unknown

$49 \quad 2$

$125 \quad 3$

$84 \quad 4$

36627

T classification

$\mathrm{T} 1$

$\mathrm{T} 2$

$\mathrm{T} 3$

$\mathrm{T} 4$

$74 \quad 3$

$279 \quad 7$

0.001

0.001

1898

121

$279 \quad 15$

$95 \quad 10$

0.001

$<0.001$

PTC nodule number

$\begin{array}{lll}\text { Single } & 345 & 6 \\ \text { Multiple } & 57 & 6\end{array}$

Capsule invasion

Presence

Absence

$194 \quad 10$

$208 \quad 2$

Strap muscles invasion

Presence

$40 \quad 6$

Absence

3626

RLN invasion

Presence

Absence

$$
92
$$

0.001

Esophagus invasion $393 \quad 10$

Presence

$6 \quad 2$

$<0.001$ 
Table 2 Relationship between serum fibrinogen levels and clinical characteristics in the training and testing sets of PTC patients (Continued)

\begin{tabular}{|c|c|c|c|c|c|c|}
\hline \multirow[b]{3}{*}{ Factor } & \multicolumn{3}{|c|}{ Training set } & \multicolumn{3}{|c|}{ Testing set } \\
\hline & \multicolumn{3}{|c|}{ Serum fibrinogen level } & \multicolumn{3}{|c|}{ Serum fibrinogen level } \\
\hline & Low & High & $p$ & Low & High & $p$ \\
\hline Trachea invasion & & & $<0.001$ & & & $<0.001$ \\
\hline Presence & 3 & 3 & & 11 & 5 & \\
\hline Absence & 399 & 9 & & 564 & 29 & \\
\hline N classification & & & 0.186 & & & 0.604 \\
\hline No & 193 & 3 & & 279 & 14 & \\
\hline N1a & 149 & 7 & & 183 & 14 & \\
\hline $\mathrm{N} 1 \mathrm{~b}$ & 60 & 2 & & 113 & 6 & \\
\hline M classification & & & $<0.001$ & & & $<0.001$ \\
\hline MO & 400 & 10 & & 569 & 30 & \\
\hline M1 & 2 & 2 & & 6 & 4 & \\
\hline PTC recurrence & & & 0.002 & & & 0.002 \\
\hline No & 373 & 8 & & 547 & 28 & \\
\hline Yes & 29 & 4 & & 28 & 6 & \\
\hline AJCC stage & & & 0.004 & & & 0.047 \\
\hline I & 268 & 4 & & 392 & 20 & \\
\hline$\|$ & 62 & 2 & & 100 & 3 & \\
\hline III & 70 & 4 & & 77 & 7 & \\
\hline IV & 2 & 2 & & 6 & 4 & \\
\hline
\end{tabular}

indicated the efficiency of preoperative serum fibrinogen as a predictor of PTC recurrence.

\section{Discussion}

In the present study, we analyzed the correlation between serum fibrinogen levels and tumor stage and found that in PTC, high serum fibrinogen levels $(>4 \mathrm{~g} / \mathrm{L})$ are more likely to indicate advanced PTC stage (according to TNM and invasiveness). Moreover, the results of univariate and multivariate analyses indicated that high serum fibrinogen levels are an independent risk factor for PTC recurrence. Finally, using these risk factors, we developed a nomogram to predict the risk of recurrence. To our knowledge, this is the first study to focus on the relationship between serum fibrinogen levels and PTC stage or recurrence with the aim of building a Nomogram. Most importantly, we validated our results in a testing set consisting of a large number of patients. Similar outcomes and conclusions were obtained for the testing and training sets.

Our data show that hyperfibrinogenemia is significantly associated with advanced pathological tumor stage, lymph node metastasis, and adjoining tissue or organ invasion. These findings are consistent with those reported in previous studies examining cancers in other organs [25-27]. Zhang et al. focused on plasma fibrinogen levels in esophageal squamous cell carcinoma and found that patients with hyperfibrinogenemia were more likely to have an advanced pathological $\mathrm{T}$ stage, lymph node metastasis and distant metastasis [26]. These results are similar to those reported in studies by Luo et al. that focused on histology in esophageal cancer [25, 28], gastric cancer [29], lung cancer [10] and urothelial carcinoma [30]. In our previous study [31], we reported that hyperfibrinogenemia was associated with a higher rate of lymph node and capsule invasion in medullary thyroid carcinoma. To our knowledge, this is the first study to explore serum fibrinogen levels in PTC. In cancer, hyperfibrinogenemia may also be associated with a higher risk of metastasis, as reported by Zhang et al. [26], who found that esophageal cancer patients with hyperfibrinogenemia exhibited a 2.5 -fold increased relative risk of distant metastasis.

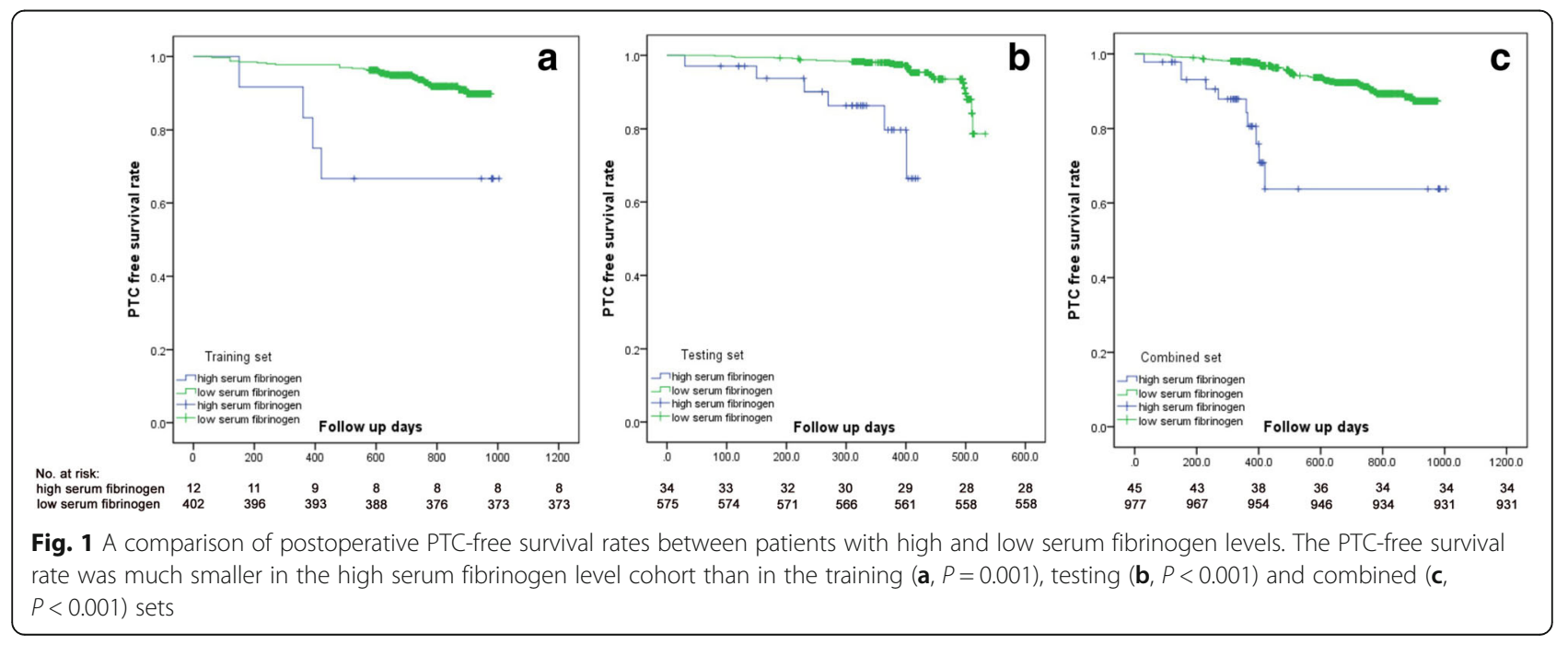


Table 3 Univariate Cox regression analysis for PTC recurrence in the training and testing patient sets

\begin{tabular}{|c|c|c|c|c|}
\hline & Training set & & Testing set & \\
\hline Factor & $\mathrm{HR}(95 \% \mathrm{Cl})$ & $p$ & $\mathrm{HR}(95 \% \mathrm{Cl})$ & $p$ \\
\hline All patients & 414 & & 609 & \\
\hline Age (years) & & 0.622 & & 0.753 \\
\hline$\leq 45$ & 1 (reference) & & 1 (reference) & \\
\hline$>45$ & 0.982 (0.457 to 1.452 ) & & $0.872(0.562$ to 1.654$)$ & \\
\hline Age (years) & & 0.672 & & 0.261 \\
\hline$\leq 55$ & 1 (reference) & & 1 (reference) & \\
\hline$>55$ & 1.524 (0.782 to 2.281$)$ & & 1.622 (0.891 to 2.462$)$ & \\
\hline Gender & & 0.321 & & 0.271 \\
\hline Female & 1 (reference) & & 1 (reference) & \\
\hline Male & 1.451 (0.661 to 2.992 ) & & 1.652 (0.842 to 2.721$)$ & \\
\hline Postoperative RAI & & 0.172 & & 0.283 \\
\hline Yes & 1 (reference) & & 1 (reference) & \\
\hline No & 0.872 (0.521 to 1.726$)$ & & 0.982 (0.475 to 2.228$)$ & \\
\hline Race & & 0.372 & & 0.208 \\
\hline Han & 1 (reference) & & 1 (reference) & \\
\hline Other & 1.211 (0.872 to 1.872$)$ & & 1.253 (0.772 to 2.011$)$ & \\
\hline BRAF mutation & & 0.382 & & 0.229 \\
\hline Positive & 1 (reference) & & 1 (reference) & \\
\hline Negative & 0.871 (0.622 to 1.263$)$ & & $0.982(0.821$ to 1.461$)$ & \\
\hline T classification & & 0.021 & & 0.008 \\
\hline $\mathrm{T} 1-2$ & 1 (reference) & & 1 (reference) & \\
\hline T3-4 & 3.261 (1.271 to 5.653$)$ & & $3.876(1.532$ to 6.211$)$ & \\
\hline PTC nodule number & & 0.152 & & 0.102 \\
\hline Single & 1 (reference) & & 1 (reference) & \\
\hline Multiple & 1.933 (0.891 to 2.901) & & 2.011 (0.902 to 3.110$)$ & \\
\hline N classification & & 0.048 & & 0.041 \\
\hline NO & 1 (reference) & & 1 (reference) & \\
\hline N1 & 1.502 (1.029 to 2.893$)$ & & $1.462(1.081$ to 3.011$)$ & \\
\hline M classification & & $<0.001$ & & $<0.001$ \\
\hline Mo & 1 (reference) & & 1 (reference) & \\
\hline M1 & 8.662 (3.092 to 16.223 ) & & 9.920 (3.825 to 21.273$)$ & \\
\hline Serum fibrinogen levels & & 0.012 & & 0.007 \\
\hline Low & 1 (reference) & & 1 (reference) & \\
\hline High & 3.457 (2.203 to 6.782$)$ & & $4.228(2.102$ to 7.541$)$ & \\
\hline
\end{tabular}

In our study, we also show that hyperfibrinogenemia is a risk factor for PTC recurrence. Yamamoto and colleagues [32] compared the efficiency of plasma fibrinogen levels to that of other prognostic markers for predicting gastric cancer recurrence, and their results indicated that plasma fibrinogen level was the most efficient of seven known prognostic markers (the others were carcinoembryonic antigen, carbohydrate antigen 19-9, and C-reactive protein levels, platelet counts, the platelet-to-lymphocyte and neutrophil-to-lymphocyte ratio) for predicting recurrence. Pre-transplant elevated plasma fibrinogen levels constitute a novel prognostic predictor of hepatocellular carcinoma after liver transplantation [33]. Similar correlations have also been observed between hyperfibrinogenemia and recurrence of renal cell carcinoma [34] and other human cancers [35].

Several mechanisms may explain the observed impact of hyperfibrinogenemia. First, fibrinogen may facilitate interactions between cancer and host cells and thereby facilitate metastasis [29]. Second, fibrinogen may help 
Table 4 Multivariate analysis of factors that contributed to PTC recurrence in the training and testing sets

\begin{tabular}{llll}
\hline Variables & Odds ratio & $95 \% \mathrm{Cl}$ & \\
\hline Training set $(n=414)$ & & & \\
Serum fibrinogen levels (high vs low) & 3.152 & $1.781-5.882$ & 0.002 \\
T classification & 4.117 & $1.340-9.831$ & $<0.001$ \\
N classification & 1.682 & $1.132-2.862$ & 0.046 \\
M classification & 11.681 & $5.684-32.391$ & $<0.001$ \\
Testing set (n=609) & & & 0.032 \\
Serum fibrinogen levels (high vs low) & 2.891 & $1.201-4.874$ & 0.001 \\
T classification & 3.872 & $1.227-10.862$ & 0.042 \\
N classification & 1.621 & $1.201-2.984$ & $<0.001$ \\
M classification & 13.772 & $4.823-28.910$ & \\
\hline
\end{tabular}

cancer cells evade innate immune cells [20]. Third, a positive feedback loop may exist between fibrinogen and inflammation [36]. Fourth, fibrinogen may enhance tumor progression by inducing tumor cell proliferation, migration and angiogenesis [18, 19]. Finally, fibrinogen surrounding tumor cells may serve as a scaffold that binds members of growth factor families, which may contribute to tumor proliferation and stimulate angiogenesis [37].

We developed a nomogram based on the identified risk factors because a nomogram allows data to be more easily visualized and used in a clinical setting. This nomogram may also be useful for designing follow-up protocols or postoperative adjuvant therapy regiments, such as TSH suppressive therapy or 131I radioactive therapy. Moreover, this model may facilitate communication between surgeons and their patients or the families of patients regarding prognostic analyses and postoperative sequential therapy [38]. To use this nomogram, a PTC patient's value is located on the corresponding variable axis, and a vertical line is drawn upwards to obtain the number of total points. All of the points for the variable are then added, and then the sum of these numbers is allocated in the Risk axis. A prediction regarding the possibility of PTC recurrence can thereby be calculated in every PTC case.

However, this study has several limitations. First, this is a retrospective research study that focused on data from a single center, which may had resulted in selection bias. However, the large size of the PTC patient cohort may have reduced this bias. Moreover, we select 609 cases to use as a testing cohort to effectively validate our

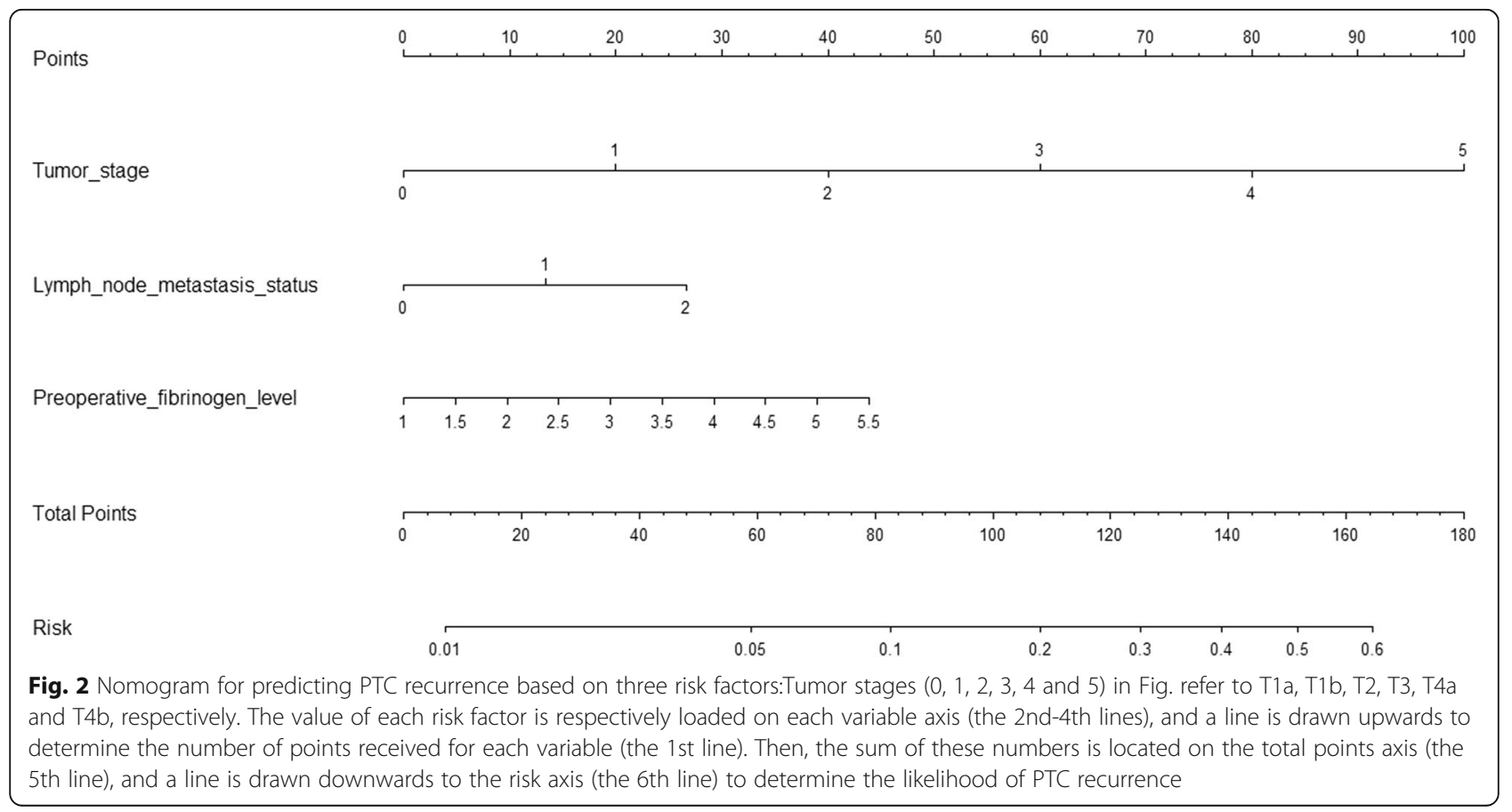


results. Second, our results were only validated using data from our center, and this may limit its usefulness in other centers. However, we are currently performing a study using data across multiple centers in the hope of obtaining more objective results. Last, we cannot provide information regarding recurrence site due to the retrospective study design as most of this information was not recorded.

\section{Conclusion}

In conclusion, we found that hyperfibrinogenemia is highly correlated with advanced TNM stage and a higher recurrence rate in PTC patients. Our nomogram, which was based on the risk factors identified in this study, objectively and accurately predicted PTC recurrence.

\section{Abbreviations}

ATA: American Thyroid Association; LNM: Lymph node metastasis; PTC: Papillary thyroid carcinoma; US: Ultrasonography

\section{Acknowledgements}

Not applicable.

\section{Funding}

This study was supported by grants from the National Key R\&D Program of China (2017YFC0907504), National Natural Science Foundation (81702646), Sichuan Province Science and Technology Project of China (No. 2017SZ0139), Sichuan University for youth fund (2017SCU11016), Health and Family Planning Commission of Sichuan Province (17PJ398), and Postdoctoral Sustentation Fund of Sichuan University (2017SCU12035).

\section{Availability of data and materials}

All data generated or analyzed during this study are available from the corresponding author upon reasonable request.

\section{Authors' contributions}

The first author of this manuscript is LJ. ZJQ, LZH and GRX conceived and performed most of the surgeries; ZJQ, LZH and GRX provided the study materials or patients; LJY collected and assembled the data; LJY performed the data analysis and interpretation, and ZJQ provided comments and critical revisions. All authors have read and approved the final version of this manuscript.

\section{Ethics approval and consent to participate}

The research was reviewed and approved by the Ethics Committee of West China Hospital. All procedures in the study involving human participants were performed in accordance with the ethical standards of West China Hospital and/or the national research committee, as well as the 1964 Helsinki Declaration and its later amendments or comparable ethical standards. Before collecting human samples, all participants signed informed consent forms according to our institutional guidelines.

\section{Consent for publication}

Not applicable.

\section{Competing interests}

The authors declare that they have no competing interests.

No benefits in any form have been received or will be received from a commercial party related directly or indirectly to the subject of this article.

\section{Publisher's Note}

Springer Nature remains neutral with regard to jurisdictional claims in published maps and institutional affiliations.
Received: 3 October 2017 Accepted: 22 March 2018

Published online: 05 April 2018

\section{References}

1. Chen W, Zheng R, Baade PD, Zhang S, Zeng H, Bray F, Jemal A, Yu XQ, He J. Cancer statistics in China, 2015. CA Cancer J Clin. 2016;66(2):115-32.

2. Haugen BR, Alexander EK, Bible KC, Doherty GM, Mandel SJ, Nikiforov YE, Pacini F, Randolph GW, Sawka AM, Schlumberger M, et al. 2015 American Thyroid Association management guidelines for adult patients with thyroid nodules and differentiated thyroid Cancer: the American Thyroid Association guidelines task force on thyroid nodules and differentiated thyroid Cancer. Thyroid. 2016;26(1):1-133.

3. McLeod DS, Sawka AM, Cooper DS. Controversies in primary treatment of low-risk papillary thyroid cancer. Lancet. 2013;381(9871):1046-57.

4. Mehanna H, Al-Maqbili T, Carter B, Martin E, Campain N, Watkinson J, McCabe C, Boelaert K, Franklyn JA. Differences in the recurrence and mortality outcomes rates of incidental and nonincidental papillary thyroid microcarcinoma: a systematic review and meta-analysis of 21329 personyears of follow-up. J Clin Endocrinol Metab. 2014;99(8):2834-43.

5. Kwak JY, Kim EK, Kim MJ, Son EJ, Chung WY, Park CS, Nam KH. Papillary microcarcinoma of the thyroid: predicting factors of lateral neck node metastasis. Ann Surg Oncol. 2009:16(5):1348-55.

6. Watkinson JC, Franklyn JA, Olliff JF. Detection and surgical treatment of cervica lymph nodes in differentiated thyroid cancer. Thyroid. 2006;16(2):187-94.

7. Hwang HS, Orloff LA. Efficacy of preoperative neck ultrasound in the detection of cervical lymph node metastasis from thyroid cancer. Laryngoscope. 2011;121(3):487-91.

8. Kim I, Kim HG, Kim H, Kim HH, Park SK, Uhm CS, Lee ZH, Koh GY. Hepatic expression, synthesis and secretion of a novel fibrinogen/angiopoietinrelated protein that prevents endothelial-cell apoptosis. Biochem J. 2000; 346(Pt 3):603-10.

9. Mosesson MW. Fibrinogen and fibrin structure and functions. J Thromb Haemost. 2005:3(8):1894-904.

10. Sheng L, Luo M, Sun X, Lin N, Mao W, Su D. Serum fibrinogen is an independent prognostic factor in operable nonsmall cell lung cancer. Int Cancer. 2013;133(11):2720-5.

11. Yamashita H, Kitayama J, Taguri M, Nagawa H. Effect of preoperative hyperfibrinogenemia on recurrence of colorectal cancer without a systemic inflammatory response. World J Surg. 2009;33(6):1298-305.

12. Polterauer S, Seebacher V, Hefler-Frischmuth K, Grimm C, Heinze G, Tempfer C, Reinthaller A, Hefler L. Fibrinogen plasma levels are an independent prognostic parameter in patients with cervical cancer. Am J Obstet Gynecol. 2009;200(6):647 e641-7.

13. Polterauer S, Grimm C, Seebacher V, Concin N, Marth C, Tomovski C, Husslein H, Leipold H, Hefler-Frischmuth K, Tempfer C, et al. Plasma fibrinogen levels and prognosis in patients with ovarian cancer: a multicenter study. Oncologist. 2009;14(10):979-85.

14. Takeuchi H, Ikeuchi S, Kitagawa Y, Shimada A, Oishi T, Isobe Y, Kubochi K, Kitajima M, Matsumoto S. Pretreatment plasma fibrinogen level correlates with tumor progression and metastasis in patients with squamous cell carcinoma of the esophagus. J Gastroenterol Hepatol. 2007;22(12):2222-7.

15. Guo Q, Zhang B, Dong X, Xie Q, Guo E, Huang H, Wu Y. Elevated levels of plasma fibrinogen in patients with pancreatic cancer: possible role of a distant metastasis predictor. Pancreas. 2009;38(3):e75-9.

16. Yamashita H, Kitayama J, Kanno N, Yatomi Y, Nagawa $H$. Hyperfibrinogenemia is associated with lymphatic as well as hematogenous metastasis and worse clinical outcome in T2 gastric cancer. BMC Cancer. 2006;6:147.

17. Tang L, Liu K, Wang J, Wang C, Zhao P, Liu J. High preoperative plasma fibrinogen levels are associated with distant metastases and impaired prognosis after curative resection in patients with colorectal cancer. J Surg Oncol. 2010;102(5):428-32

18. Steinbrecher KA, Horowitz NA, Blevins EA, Barney KA, Shaw MA, HarmelLaws E, Finkelman FD, Flick MJ, Pinkerton MD, Talmage KE, et al. Colitisassociated cancer is dependent on the interplay between the hemostatic and inflammatory systems and supported by integrin alpha(M)beta(2) engagement of fibrinogen. Cancer Res. 2010;70(7):2634-43.

19. Martino MM, Briquez PS, Ranga A, Lutolf MP, Hubbell JA. Heparin-binding domain of fibrin(ogen) binds growth factors and promotes tissue repair when incorporated within a synthetic matrix. Proc Natl Acad Sci U S A. 2013;110(12):4563-8 
20. Nieswandt B, Hafner M, Echtenacher B, Mannel DN. Lysis of tumor cells by natural killer cells in mice is impeded by platelets. Cancer Res. 1999;59(6): 1295-300.

21. Lei J, Zhong J, Jiang K, Li Z, Gong R, Zhu J. Skip lateral lymph node metastasis leaping over the central neck compartment in papillary thyroid carcinoma. Oncotarget. 2017:8(16):27022-33.

22. Lei J, Zhu J, Li Z, Gong R, Wei T. Surgical procedures for papillary thyroid carcinoma located in the thyroid isthmus: an intention-to-treat analysis, OncoTargets and therapy. 2016;9:5209-16.

23. Kim SK, Park I, Hur N, Choe JH, Kim JH, Kim JS. Patterns, predictive factors and prognostic impact of multilevel metastasis in N1b papillary thyroid carcinoma. Br J Surg. 2017;104(7):857-67.

24. Lee YM, Sung TY, Kim WB, Chung KW, Yoon JH, Hong SJ. Risk factors for recurrence in patients with papillary thyroid carcinoma undergoing modified radical neck dissection. Br J Surg. 2016;103(8):1020-5.

25. Zhang SS, Lei YY, Cai XL, Yang H, Xia X, Luo KJ, Su CH, Zou JY, Zeng B, Hu $Y$, et al. Preoperative serum fibrinogen is an independent prognostic factor in operable esophageal cancer. Oncotarget. 2016;7(18):25461-9.

26. Zhang D, Zhou X, Bao W, Chen Y, Cheng L, Qiu G, Sheng L, Ji Y, Du X. Plasma fibrinogen levels are correlated with postoperative distant metastasis and prognosis in esophageal squamous cell carcinoma. Oncotarget. 2015;6(35):38410-20.

27. Wang J, Liu H, Shao N, Tan B, Song Q, Jia Y, Cheng Y. The clinical significance of preoperative plasma fibrinogen level and platelet count in resectable esophageal squamous cell carcinoma. World J Surg Oncol. 2015;13:157.

28. Matsuda S, Takeuchi H, Kawakubo H, Fukuda K, Nakamura R, Takahashi T, Wada N, Saikawa Y, Omori T, Kitagawa Y. Cumulative prognostic scores based on plasma fibrinogen and serum albumin levels in esophageal cancer patients treated with transthoracic esophagectomy: comparison with the Glasgow prognostic score. Ann Surg Oncol. 2015;22(1):302-10.

29. Yu X, Hu F, Yao Q, Li C, Zhang H, Xue Y. Serum fibrinogen levels are positively correlated with advanced tumor stage and poor survival in patients with gastric cancer undergoing gastrectomy: a large cohort retrospective study. BMC Cancer. 2016;16:480.

30. Tanaka N, Kikuchi E, Matsumoto K, Hayakawa N, Ide H, Miyajima A, Nakamura S, Oya M. Prognostic value of plasma fibrinogen levels in patients with localized upper tract urothelial carcinoma. BJU Int. 2013;111(6):857-64.

31. Jiang K, Lei J, Li C, Shu K, Li W, Zhang Y, Li Z, Gong R, Zhu J. Comparison of the prognostic values of selected inflammation based scores in patients with medullary thyroid carcinoma: a pilot study. J Surg Oncol. 2017;116(3):281-7.

32. Yamamoto M, Kurokawa Y, Miyazaki Y, Makino T, Takahashi T, Yamasaki M, Nakajima K, Takiguchi S, Mori M, Doki Y. Usefulness of preoperative plasma fibrinogen versus other prognostic markers for predicting gastric Cancer recurrence. World J Surg. 2016:40(8):1904-9.

33. Wang GY, Jiang N, Yi HM, Wang GS, Zhang JW, Li H, Zhang J, Zhang Q, Yang Y, Chen GH. Pretransplant elevated plasma fibrinogen level is a novel prognostic predictor for hepatocellular carcinoma recurrence and patient survival following liver transplantation. Ann Transpl. 2016;21:125-30

34. Obata J, Tanaka N, Mizuno R, Kanao K, Mikami S, Matsumoto K, Kosaka T, Kikuchi E, Jinzaki M, Oya M. Plasma fibrinogen level: an independent prognostic factor for disease-free survival and cancer-specific survival in patients with localised renal cell carcinoma. BJU Int. 2016;118(4):598-603.

35. Perisanidis C, Psyrri A, Cohen EE, Engelmann J, Heinze G, Perisanidis B, Stift A, Filipits $M$, Kornek G, Nkenke E. Prognostic role of pretreatment plasma fibrinogen in patients with solid tumors: a systematic review and metaanalysis. Cancer Treat Rev. 2015;41(10):960-70.

36. Yamashita H, Kitayama J, Nagawa H. Hyperfibrinogenemia is a usefu predictor for lymphatic metastasis in human gastric cancer. Jpn J Clin Oncol. 2005:35(10):595-600.

37. Witsch E, Sela M, Yarden Y. Roles for growth factors in cancer progression. Physiology (Bethesda). 2010;25(2):85-101.

38. Li J, Zhou J, Yang PH, Xia Y, Shi YH, Wu D, Lv G, Zheng W, Wang K, Wan XY, et al. Nomograms for survival prediction in patients undergoing liver resection for hepatitis $B$ virus related early stage hepatocellular carcinoma. Eur J Cancer. 2016;62:86-95.

\section{Submit your next manuscript to BioMed Central and we will help you at every step:}

- We accept pre-submission inquiries

- Our selector tool helps you to find the most relevant journal

- We provide round the clock customer support

- Convenient online submission

- Thorough peer review

- Inclusion in PubMed and all major indexing services

- Maximum visibility for your research

Submit your manuscript at www.biomedcentral.com/submit

) Biomed Central 